\title{
Design de jogos digitais educacionais e a motivação do aprendiz
}

\author{
The design of educational digital games and learner's motivation
}

\author{
CEZAROTTO, Matheus A.; Mestre em design; Universidade Federal do Paraná \\ matheus.cezarotto@gmail.com
}

ALVES, Marcia M.; Doutora em design; Universidade Federal do Paraná

alvesmarcia@gmail.com

\begin{abstract}
Resumo
No contexto educacional, a falta de motivação do aprendiz se caracteriza como um dos maiores problemas para a concretização do aprendizado, diante disso jogos digitais educacionais têm sido idealizados e utilizados como uma alternativa. Contudo, apesar das significativas possibilidades de uso do jogo enquanto um recurso educacional motivador, na literatura pouco se tem discutido sobre como desenvolver jogos capazes de motivar e manter o aprendiz motivado no ambiente educacional. Diante disso, o objetivo, deste artigo foi apresentar uma categorização sobre a motivação do aprendiz, com o intuito de auxiliar no design desses jogos. Para isto, o artigo está alicerçado em uma revisão bibliográfica narrativa que considerou as relações estabelecidas entre quatro estudos notórios sobre motivação. A categorização gerada demonstra-se ser uma ferramenta útil para o design de jogos, bem como para a pesquisa desse fenômeno com o usuário.
\end{abstract}

Palavras Chave: motivação; design de jogo; jogos educacionais.

\begin{abstract}
In education field, the lack of motivation among learners is one of the biggest problems faced by the educational system. In this sense, researchers and educational specialists have been use educational digital games as an alternative. However, despite the significant possibilities when using games for educational purposes, in the literature only a few researchers have been investigating about how to develop educational game capable of foster motivation and also maintain the learner initial motivation. Thus, this paper aims to propose a categorization for the learners' motivation, in order to be useful for developers during the design of these games. In order to achieve it, this paper is based on a narrative literature review that covers four well-know studies about motivation and their relationship. As a result, we propose a categorization of motivation that represents to be a useful tool for the design of educational games, moreover it is useful to research motivation with learners.
\end{abstract}

Keywords: motivation; game design; educational games 


\section{Introdução}

Ao pesquisar sobre o aprimoramento das práticas de ensino-aprendizagem, argumenta-se como necessário considerar que tanto os aprendizes como os professores estão inseridos na cibercultura. Esse fenômeno sociocultural, surge da relação entre a sociedade, a cultura e as tecnologias digitais (LEMOS e CUNHA, 2003). Tais tecnologias constantemente são atualizadas, o que implica em reconfigurações nas mais variadas atividades da sociedade (e.g. uso de dispositivos móveis, comunicação instantânea). Dentre essas tecnologias, o foco deste artigo está no jogo digital educacional, que faz parte das novas tecnologias de informação e comunicação (TIC), ademais atua como um recurso digital motivador para a aprendizagem.

O Jogo digital é reconhecido como uma mídia de entretenimento significativa por proporcionar ao usuário diversão e engajamento em um ambiente multimídia motivador (TOBIAS et al. 2014). Diante disso, pesquisadores (e.g. De FREITAS e LIAROKAPIS, 2011; MAYER, 2014) visualizam o potencial de motivação ofertado pelos jogos, para ensinar e treinar conteúdos para os mais variados públicos e contextos. Cabe salientar que apesar da recente ascensão do jogo digital educacional em razão do desenvolvimento tecnológico, o seu potencial para motivar e ensinar não é novidade, como pode ser visto nas pesquisas de Abt (1987).

Contudo, existe uma separação expressiva entre os jogos digitais educacionais (objetivo educacional claro) e os jogos para o puro entretenimento. Para Mattar (2010) os jogos de caráter educacional em sua grande maioria são considerados chatos pelos aprendizes. Além disso, observa-se que os jogos educacionais usualmente são pouco atrativos e não conseguem fomentar e manter a motivação inicial do aprendiz ao longo da atividade.

Considerando isso, este artigo tem como objetivo propor uma categorização teórica sobre os componentes de motivação do aprendiz, para auxiliar no design de jogos digitais educacionais. Para tanto, a pesquisa caracteriza-se como de natureza básica e com objetivo exploratório. Como procedimento metodológico é utilizada uma revisão bibliográfica narrativa. Destaca-se que este estudo está alicerçado na etapa inicial, já finalizada, da tese em andamento do primeiro autor deste artigo. Isso posto, no contexto do P\&D 2018, o presente artigo se enquadra no eixo Design e Ensino-aprendizagem, no tópico abordagens tecnológicas. Este artigo está estruturado da seguinte forma: (1) Introdução; (2) Elementos do jogo digital educacional; (3) Motivação para a aprendizagem; (4) Proposta para o estudo da motivação do aprendiz no jogo digital educacional; (5) Considerações finais.

\section{Elementos do jogo digital educacional}

Neste artigo o jogo digital educacional é compreendido como o jogo desenvolvido para promover a aprendizagem de algum conteúdo específico, ou seja, possui um propósito educacional claro (MAYER, 2014). Ressalta-se que a aprendizagem no jogo digital educacional tem como base uma proposta pedagógica explícita, que busca ensinar algo de forma lúdica (CLUA e BITTENCOURT, 2004). Para tanto, tais jogos apresentam o conteúdo pedagógico em uma estrutura composta pelas características dos jogos de entretenimento (interatividade, desafios, regras, progresso, feedback) (MAYER, 2014; KAPP, 2012). Tal fato está representado na figura 1. 
Figura 1 - Síntese gráfica da base dos jogos digitais educacionais

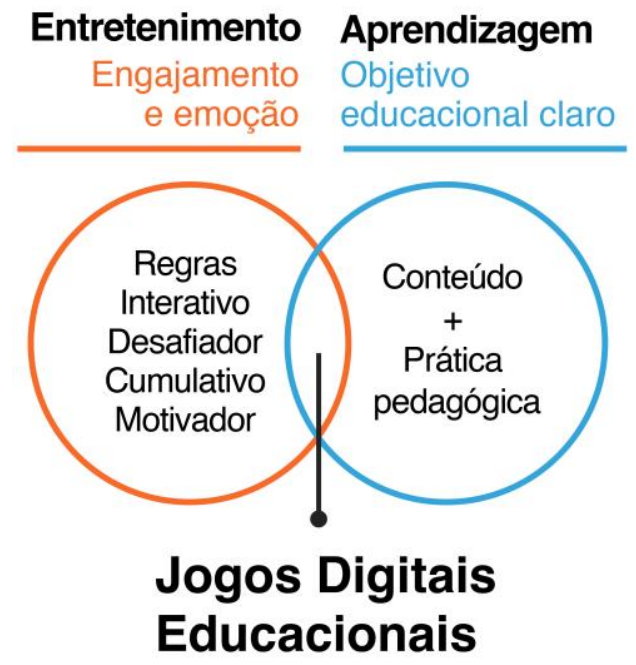

Fonte: o autor com base em Mayer (2014); Kapp (2014); Clua e Bittencourt (2004)

Os elementos que compõem o jogo digital educacional são segmentados em duas categorias, a saber: Elementos de entretenimento e Elementos educacionais. Cabe destacar que apesar da categorização os elementos estão interconectados.

Na categoria entretenimento, Fullerton, Swains e Hoffman (2004) organizam os elementos de jogo como elementos formais ou elementos dramáticos. Os elementos formais (tradução nossa, do inglês formal elements) são aqueles que representam a estrutura funcional no sistema de jogo, os quais permitem diversas combinações. Em complemento, para este artigo, também se considera os nove elementos de jogo pontuados por Järvinen (2008). Ainda como elementos de entretenimento, Fullerton, Swains e Hoffman (2004) argumentam que para desenvolver jogos que sejam significativos para os jogadores, isto é, que sejam capazes de capturar a imaginação dos jogadores tornando a experiência emocionalmente motivadora, são necessários os elementos dramáticos (tradução nossa, do inglês dramatic elements). Com base nos estudos mencionados, realizou-se uma convergência entre os elementos evidenciados pelos autores, vide tabela 1. Destaca-se que ambos os autores pesquisados mencionam as recompensas de jogo como parte dos elementos formais, atuando como uma informação de jogo (e.g. resultado). Contudo, quando o assunto é a motivação do jogador, compreende-se o elemento "recompensas" como parte dos elementos dramáticos de jogo.

Tabela 1 - Elementos de entretenimento em jogos digitais

\begin{tabular}{ll}
\hline Categorias de elementos (entretenimento) & Elementos \\
\hline Elementos Formais & $\begin{array}{l}\text { Jogadores; Objetivos; Procedimentos; Regras; Recursos; } \\
\text { Conflito; Fronteiras; Resultado; Componentes; Mecânicas; } \\
\text { Informação; Tema; Interface virtual; Contexto. }\end{array}$ \\
\hline Elementos Dramáticos & $\begin{array}{l}\text { Desafio; Brincar; Premissa; Personagem; História } \\
\text { Mundo ficcional; Arco dramático; Recompensas }\end{array}$ \\
\hline
\end{tabular}


Por outro lado, os elementos educacionais de jogo são representados pela definição do conteúdo, da abordagem pedagógica e do objetivo educacional, de acordo com Winn (2008); e Chamberlin, Trespalacios e Gallagher (2012). Pontuamos que essas definições não representam elementos específicos no sistema de jogo, mas sim norteiam a configuração de todos os elementos de jogo. Para tanto, são orientadas por informações do perfil cognitivo do aprendiz, do ambiente de uso do jogo e o do processo de refinamento dos objetivos de aprendizagem.

Diante disto, argumenta-se que a forma como tais elementos de jogo (entretenimento + educacionais) são configurados pela equipe de desenvolvimento, influencia diretamente na motivação a ser estimulada no aprendiz para o uso do jogo. Nesse sentido, a seguir são detalhados aspectos teóricos sobre a construção da motivação do usuário, ao considerá-la como parte da experiência do jogador e a sua relação com os elementos aqui apresentados.

\section{Motivação para a aprendizagem}

Um dos problemas centrais da educação é a falta de motivação do aprendiz, tal problema atinge todos os níveis de ensino, de acordo com Guimarães e Bzuneck (2008). Nesse contexto, o jogo digital educacional é visto como uma alternativa para motivar tais aprendizes, em especial pelo uso da linguagem digital ser popular entre as novas gerações, os chamados nativos digitais (PRENSKY, 2012).

Entretanto, concorda-se com Arnseth (2006) quando ele argumenta que o jogo (mesmo quando educacional) por si só não deve ser considerado como um artefato que promove e estimula uma aprendizagem mais significativa, divertida e prazerosa. Ademais, evita-se seguir o que Clua e Bittencourt (2004) denominam como "joguismo" (grifo dos autores), isto é, compreender o jogo digital educacional como a única tecnologia capaz de desenvolver as habilidades dos aprendizes, ou ainda como a solucionadora de todos os problemas educacionais. Portanto, neste artigo compreende-se o jogo digital educacional como uma tecnologia educacional que possibilita significativas oportunidades de aprendizagem, quando aliada a outras abordagens pedagógicas, bem como quando desenvolvida e configurada adequadamente.

Nesse sentido, Savi (2011) ressalta que para um jogo educacional ser considerado de qualidade ele necessita possuir objetivos educacionais claros, motivar os aprendizes para os estudos e fomentar a aprendizagem de conteúdos curriculares por meio de atividade divertidas, prazerosas e desafiadoras.

Portanto, de modo a fomentar a qualidade do jogo digital educacional é elementar considerar a motivação do aprendiz como parte de sua experiência. $O$ que abrange o seu interesse inicial em utilizar o jogo, bem como a permanência do seu interesse ao longo das atividades pedagógicas de jogo. Assim, pelo viés do game design busca-se estruturar um arcabouço teórico sobre motivação e a sua relação com os elementos de jogo. Para isto, inicialmente é caracterizado o conceito de motivação.

\subsection{Motivação como parte da experiência do aprendiz}

Reeve (2009) defende que o conceito de motivação está atrelado ao porque as pessoas realizam determinadas atividades, ou seja, qual é o motivo dessa realização. Isso posto, entendese a motivação como o que energiza o comportamento de um indivíduo para a realização de uma determinada atividade, bem como o que o direciona para essa realização. Para o referido autor, os processos que energizam e direcionam o comportamento humano para uma atividade 
são gerados por dois motivos, a saber: os internos (individuais) e os externos (ambiente). Essa categorização entre motivos internos e externos, é mais conhecida na literatura como tipos de motivação, que são: motivação intrínseca e motivação extrínseca.

A motivação intrínseca emerge espontaneamente nas pessoas para o seu desenvolvimento e ocorre por meio de suas necessidades psicológicas e inatas (REEVE, 2009). Para Malone e Lepper (1987) uma pessoa está intrinsecamente motivada quando ela está engajada na atividade por sua conta própria, isto é, o indivíduo não busca receber estímulos externos como recompensas ou ainda, para evitar alguma punição externa. Assim, para os autores, o indivíduo motivado intrinsecamente descreve a atividade como, divertida, interessante, cativante e prazerosa.

Em contraste, Reeve (2009) explica que a motivação extrínseca surge por meio dos incentivos e consequências do ambiente como, por exemplo, dinheiro, atenção, adesivos, notas, bolsas de estudos, doces, prêmios, etc. Esses incentivos, atuam como razões para que uma pessoa comece e ou persista em uma determinada atividade, ou seja, um atrativo para estimular um comportamento motivado. A motivação extrínseca surge de consequências que estão separadas da atividade por si só. Assim, diferente da motivação intrínseca, na motivação extrínseca o indivíduo não se engaja em uma atividade pela simples satisfação pessoal que ao realizá-la irá Ihe proporcionar, mas por razões externas.

Argumenta-se que no jogo digital educacional o interesse está na motivação intrínseca, pois ela é considerada a motivação verdadeira, uma vez que a pessoa permanece em ação na atividade mesmo após o estímulo externo cessar, de acordo com Alves e Battaiola (2011). Dessa forma, os autores citados, ressaltam que o desafio não está em motivar uma pessoa em determinada atividade, mas sim em manter a motivação intrínseca inicial ao longo dessa atividade. Nesse sentido, percebe-se que recursos como recompensas e outros tipos específicos de feedback de jogo, caracterizados como estímulos extrínsecos, podem atuar para manter a motivação do jogador. Corroborando com isso, Habgood e Ainsworth (2011) salientam que os jogos digitais educacionais modernos permitem utilizar de recompensas e estímulos externos de forma autônoma no sistema de jogo, os quais possibilitam energizar a motivação interna no jogador nas atividades de jogo.

Neste artigo, são utilizados quatro subsídios teóricos centrais para delinear um arcabouço teórico sobre como promover e ampliar a motivação do aprendiz em jogos digitais educacionais, a saber: (1) teoria do fluxo (CSIKSZENTMIHALYI, 1990); (2) Autoeficácia (BANDURA, 2016); (3) Taxonomia proposta por Malone e Lepper (1987); (4) Modelo ARCS (KELLER, 2010). A seguir tais subsídios teóricos são descritos.

\subsection{Teoria do Fluxo}

Na teoria do Fluxo, Csikszentmihalyi (1990) propõe como obter a "experiência ótima" (do inglês optimal experience - grifo nosso) em uma atividade. Isto é, o estado mental e o melhor desempenho do indivíduo na atividade em questão por meio de um fluxo contínuo entre desafios e habilidades. Assim, as atividades de fluxo têm como função central fomentar experiências prazerosas para as pessoas.

Essa experiência de melhor desempenho ocorre quando a mente e o corpo do indivíduo chegam aos seus limites, por meio de esforços voluntários para alcançar um objetivo valioso, que 
é considerado realista. Ou seja, as habilidades do indivíduo se encontram em um nível condizente (equilibrado) com as oportunidades de ação. Mattar (2010) ressalta que a teoria do fluxo é altamente difundida na área do game design, pois o ato de jogar supostamente envolve o jogador em um estado de fluxo, que na esfera dos jogos é mais conhecido como imersão. Desse modo, argumenta-se que o balanceamento entre as habilidades do jogador e os desafios propostos pelo sistema de jogo, caracteriza-se como o percurso para a diversão.

Como parte da teoria, Csikszentmihalyi (1990) elaborou oito componentes de experiência para fomentar o estado de fluxo. Esses componentes auxiliam na elaboração de situações capazes de motivar as pessoas para uma atividade não apenas pelo interesse de ganhos externos, mas por motivos pessoais. Os componentes estão sumarizados a seguir:

- Realização de atividades desafiadoras, porém, superáveis: as atividades contêm um conjunto de possíveis ações, caracterizadas como desafios que exigem determinadas habilidades do indivíduo, esses desafios são claros para o indivíduo que tem a oportunidade de superá-los;

- Concentração inicial na atividade: o que representa a união da pessoa com a atividade;

- Objetivos claros e feedback imediato: buscando o envolvimento completo em uma experiência de fluxo é necessário que os objetivos estejam claros e ao longo das atividades feedbacks imediatos sejam disponibilizados ao indivíduo;

- Concentração e envolvimento profundo na atividade realizada, a permitir a exclusão das demais preocupações: em uma experiência de fluxo o indivíduo esquece aspectos irrelevantes a atividade, em razão de sua fruição, assim requer uma atenção completa na tarefa;

- Sensação de controle: durante suas ações, o indivíduo não se preocupa em perder o controle ou cometer erros durante a atividade;

- Perda da consciência do real: a autoconsciência desaparece durante a experiência. Isto é, o indivíduo está altamente concentrado na atividade que esquece o seu eu;

- O senso de duração do tempo é alterado, em virtude da imersão na atividade: uma das características principais da experiência de fluxo é em relação ao tempo durante uma atividade cativante, isto é, em que existe a sensação de fruição o indivíduo tem sua noção de tempo distorcida;

- Por fim, o estado de fluxo ocorre por meio da combinação dos elementos anteriores: o que reflete em um alto nível de prazer, o qual é gratificante para o indivíduo ao dedicar suas energias.

Com base em Csikszentmihalyi (1990), salienta-se que os componentes de fluxo não necessitam ocorrer em uma ordem específica, bem como não se faz necessário a ocorrência de todos os componentes para atingir o estado de fluxo, porém quanto mais componentes maiores são as chances de se atingir o estado de fluxo.

\subsection{Taxonomia de Malone e Lepper}

A taxonomia de Malone e Lepper (1987) tem o seu foco na construção de ambientes de 
aprendizagem capazes de estimular a diversão e a aprendizagem do estudante por meio de sua motivação intrínseca. Na taxonomia são considerados duas categorias de motivação intrínseca, a saber: individuais e interpessoais. Para os autores da taxonomia, em qualquer situação de aprendizagem existem quatro tipos de motivação intrínseca individuais, a saber: desafio, curiosidade, controle, fantasia. Por outro lado, existem as motivações intrínsecas interpessoais, as quais dependem de outras pessoas para ocorrer, que são: competição, cooperação e reconhecimento. Diante do escopo deste artigo, o interesse está nas motivações individuais uma vez que o interesse de pesquisa está em jogos monousuários, as motivações são descritas a seguir com base em Malone e Lepper (1987).

- Desafio: as pessoas sentem-se motivadas intrinsecamente em uma atividade quando são instigadas a resolver desafios em um nível "ótimo" (grifo nosso), condizente com as suas habilidades. Assim, atividades com um nível de desafios intermediários, fomentarão ao indivíduo uma alta motivação intrínseca. Para os autores a efetividade dos desafios em uma atividade requer alguns componentes. Primeiramente, para uma atividade ser desafiadora ela necessita ter objetivos, os quais precisam ter resultados inesperados (não previsíveis). O indivíduo ao realizar tais objetivos, necessita receber feedback sobre a sua performance, o que gera uma melhora da sua autoestima e o estimula a se engajar e/ou continuar na atividade;

- Curiosidade: é considerado o fator para motivação intrínseca mais direto para aprendizagem. Os autores abordam dois tipos de curiosidade, a saber: sensorial e emocional. A curiosidade sensorial, envolve a atração da atenção do aprendiz por meio de variações sensoriais na luz, som, ou outro estimulo sensorial do ambiente. Por exemplo, a interação nos jogos, cenários e ou personagem chamativos visualmente, entre outros efeitos visuais e sonoros, fazem parte da curiosidade sensorial. Por outro ado, a curiosidade cognitiva é estimulada ao fornecer informações e conhecimentos que o indivíduo ainda não possui, ou um complemento para o conhecimento prévio do aprendiz. Assim, na busca por completar o seu conhecimento ou adquirir novos, o aprendiz tem sua curiosidade cognitiva estimulada para a atividade;

- Controle: representa o poder de escolha ofertado pelo ambiente de aprendizagem para o indivíduo. Conforme Malone e Lepper (1987) as pessoas sentem-se motivadas intrinsecamente quando percebem que o ambiente ou a atividade está aberta para alterações, ou seja, possui uma certa contingência. Assim, quando o ambiente fornece diferentes níveis de escolha, gera-se uma sensação de poder e controle para o indivíduo, fatores que influenciam na sua motivação para a atividade;

- Fantasia: representa a possibilidade de gerar para o aprendiz imagens mentais sobre situações físicas ou sociais que não são reais ou presentes. Diante disso, argumenta-se que tais fatores são amplamente explorados no contexto ficcional de jogo. Malone e Lepper (1987) ressaltam a existência de dois tipos de fantasia, as exógenas e as endógenas. Em um ambiente instrucional a fantasia é exógena quando ela depende das habilidades que estão sendo aprendidas, mas ao contrário, quando as habilidades do aprendiz não dependem da fantasia, ela é endógena. 


\subsection{Autoeficácia}

Para Bzuneck (2009) a autoeficácia representa a percepção pessoal do indivíduo para às próprias capacidades como, por exemplo, inteligência, habilidades e conhecimentos. Esse mesmo autor, esclarece que o construto não diz respeito sobre o possuir ou não essas capacidades, mas sim representa o fato da pessoa acreditar que as detenha e com isso pode realizar determinada atividade. Bandura (2016) destaca que a autoeficácia representa a base para o nível de motivação de um indivíduo, pois por meio das suas crenças de autoeficácia o indivíduo direciona as suas ações com base no que mentalmente acredita que pode realizar. Assim, em uma atividade as crenças de autoeficácia influenciam as pessoas na definição dos objetivos de ação, no nível de comprometimento, na quantidade de esforço investido, bem como na sua perseverança diante as adversidades enfrentadas.

Diante do exposto, observa-se que o construto da autoeficácia permite ser utilizado como um mecanismo para fomentar e manter a motivação dos jogadores em um jogo educacional. Para tanto, o sistema de jogo pode fornecer a experiência de êxito durante o fluxo de jogo, ofertar feedback diante do progresso, bem como incentivar o jogador durante as atividades de jogo.

A experiência de êxito permite ser gerada no jogo por meio da elaboração dos desafios, explorando uma progressão na sua dificuldade. Pois, segundo Bzunek (2009), as crenças de autoeficácia de um indivíduo são estimuladas por meio da realização de tarefas com um grau de dificuldade condizente com as suas habilidades. Assim, na esfera dos jogos, desafios demasiadamente altos para o jogador tende a gerar o fracasso e são desmotivadores. Nesse sentido, ao considerar o perfil cognitivo individual de cada jogador, o sistema de jogo pode inicialmente permitir que o jogador consiga superar desafios fáceis, para gradualmente progredir no nível de dificuldade dos desafios. Argumenta-se que tal configuração favorece a percepção de autoeficácia do jogador, pois ele percebe que é por meio de seu esforço que suas capacidades estão sendo aprimoradas, o que atua como um fator motivacional. Além disso, durante as atividades de jogo, o jogador pode receber informações sobre o seu desempenho por meio de gráficos, quadros, entre outros elementos gráficos, bem como pode ser incentivado pelo sistema de jogo a continuar persistindo nas atividades, o que se caracteriza como uma persuasão verbal.

\subsection{Modelo ARCS}

O modelo ARCS - acrônimo para os termos em inglês Attention, Relevance, Confidence $e$ Satisfaction, foi elaborado por John Keller em 1984. Segundo o autor, a proposta do modelo surgiu após uma extensa revisão na literatura sobre motivação, na qual ele evidenciou que conceitos motivacionais poderiam ser agrupados com base em seus atributos compartilhados, desse modo o autor constituiu quatro categorias que dão o nome ao modelo - Atenção, Relevância, Confiança, Satisfação (KELLER, 2010). As categorias geram uma visão geral das dimensões centrais da motivação humana, com especial interesse no contexto da motivação para aprendizagem. As categorias são resumidas a seguir, com base na explicação de Keller (2010).

- Atenção: representa as variáveis para estimular e manter a curiosidade e o interesse do aprendiz. No contexto da aprendizagem, esta categoria está associada em como gerenciar e direcionar a atenção do aprendiz. Para isto, são utilizados recursos para direcionar o interesse e o foco de atenção do aprendiz para o 
estímulo ou partes do estímulo, relacionados com os objetivos de aprendizagem;

- Relevância: representa as crenças do aluno quanto a relevância da aprendizagem. A relevância fomenta a motivação, quando o aprendiz percebe a experiência de aprendizagem como pessoalmente relevante. Ou seja, para que o aprendiz se motive para aprendizagem, ele necessita considerar a lição ou a instrução como necessária e relacionada com os seus objetivos pessoais;

- Confiança: representa o nível de confiança do aprendiz para o sucesso nas atividades educacionais. Assim, mesmo que o aluno esteja atento e acredite na relevância da atividade, ele ainda não estará adequadamente motivado se não possuir confiança em suas habilidades diante da atividade. Portanto, é importante que atividade seja planejada de modo que auxilie o aprendiz a confiar em suas habilidades, ou seja, que ele perceba que pode aprender o conteúdo e ter uma experiência de sucesso na tarefa;

- Satisfação: representa os reforços e estímulos utilizados para manter o aluno motivado durante a atividade. Quando uma atividade educacional consegue atender com êxito as três categorias anteriores (atenção, relevância e confiança), os estudantes possivelmente serão motivados para aprender. Entretanto, é necessário manter a motivação inicial do aprendiz, isto é, fazer com que ele se mantenha interessado a continuar aprendendo. Para tanto, é necessário fomentar uma sensação de satisfação no aprendiz durante a experiência de aprendizagem, seja no processo ou com os resultados obtidos. Essa satisfação pode surgir de fatores intrínsecos e extrínsecos à atividade. Como fatores extrínsecos, pode-se citar como exemplo, notas, diplomas, entre outros tipos de recompensa. Por outro lado, os fatores intrínsecos são aqueles associados a autoestima do aprendiz e ao seu desejo pessoal de realizar algo. Por exemplo, dominar desafios que melhoram a sua sensação de competência, ser ouvido ou percebido, interagir positivamente com outras pessoas, etc.

\section{Proposta para o estudo da motivação do aprendiz no jogo digital educacional}

Por meio dos subsídios teóricos discutidos sobre motivação no item anterior, organizou-se em uma tabela os dados obtidos na qual foram evidenciadas as compatibilidades entre cada teoria, taxonomia e modelo. Destaca-se que os estudos têm em comum o mesmo objetivo, fomentar e manter a motivação intrínseca do aprendiz para a atividade. Nesse sentido, indicam o uso de recursos intrínsecos e extrínsecos, os quais se argumenta serem complementares no contexto do jogo digital educacional. Note-se que, por meio desse arcabouço é possível estruturar formas para estimular, bem como mensurar a motivação do aprendiz em um jogo educacional.

Ao considerar os subsídios teóricos descritos, foi elaborada uma proposta de categorização dos componentes de motivação para o design de jogos digitais educacionais. Como base para a proposta tem-se o estudo de Alves e Battaiola (2011), que elenca requisitos para a construção de animações e jogos digitais educacionais capazes de fomentar a motivação do aprendiz. Em sua proposta Alves e Battaiola (2011) estão fundamentados na teoria do fluxo (CSIKSZENTMIHALYI, 1990) e na taxonomia de Malone e Lepper (1987). Assim, a categorização aqui descrita realiza uma revisão e ampliação da proposta ao considerar também o construto da autoeficácia (BANDURA, 2016) e o modelo ARCS (KELLER, 2010). Ademais, busca-se uma relação com os elementos de jogo. 
Diante disto, organizou-se a sobreposição dos estudos sobre motivação como pode ser visto na tabela 3, além da revisão dos oito componentes listados por Alves e Battaiola (2011) são acrescentados dois componentes: Estimulação da autoeficácia (confiança); Relevância da atividade.

Tabela 3: Componentes de motivação com base na sobreposição dos estudos mapeados

\begin{tabular}{|c|c|c|c|c|}
\hline $\begin{array}{l}\text { Componente } \\
\text { de motivação }\end{array}$ & $\begin{array}{l}\text { Teoria do Fluxo } \\
\text { Csikszentmihalyi (1990) }\end{array}$ & $\begin{array}{l}\text { Taxonomia de } \\
\text { Malone e Lepper (1987) }\end{array}$ & $\begin{array}{l}\text { Modelo ARCS } \\
\text { Keller (2010) }\end{array}$ & $\begin{array}{l}\text { Autoeficácia } \\
\text { Bandura (2016) }\end{array}$ \\
\hline $\begin{array}{l}\text { 1. Inserção } \\
\text { de desafios }\end{array}$ & Desafios superáveis & $\begin{array}{l}\text { Desafio } \\
\text { (resultados inesperados) }\end{array}$ & / & / \\
\hline 2. Objetivos claros & Objetivo claros & Desafio (objetivos) & / & / \\
\hline $\begin{array}{l}\text { 3. Feedback das } \\
\text { ações }\end{array}$ & Feedback imediato & Desafio (Feedback) & Atenção & \multirow{3}{*}{$\begin{array}{l}\text { Persuasão verbal } \\
\text { (comunicação ou } \\
\text { indicação; } \\
\text { Estímulo sonoro } \\
\text { ou visual) }\end{array}$} \\
\hline $\begin{array}{l}\text { 4. Apelo } \\
\text { emocional }\end{array}$ & $\begin{array}{l}\text { Concentração profunda } \\
\text { Alteração do tempo } \\
\text { Perda da consciência }\end{array}$ & Fantasia (emoção) & Atenção & \\
\hline $\begin{array}{l}\text { 5. Processamento } \\
\text { cognitivo }\end{array}$ & / & $\begin{array}{l}\text { Fantasia (cognição) } \\
\text { Curiosidade (cognitiva) }\end{array}$ & / & \\
\hline $\begin{array}{l}\text { 6. Curiosidade } \\
\text { sensorial }\end{array}$ & $\begin{array}{l}\text { Concentração na } \\
\text { atividade }\end{array}$ & Curiosidade (sensorial) & / & / \\
\hline $\begin{array}{l}\text { 7. Controle sobre } \\
\text { a atividade }\end{array}$ & Sensação de controle & $\begin{array}{l}\text { Controle (contingência, } \\
\text { escolha e poder) }\end{array}$ & / & / \\
\hline $\begin{array}{l}\text { 8. Imersão } \\
\text { (Satisfação) }\end{array}$ & Estado de fluxo & / & Satisfação & / \\
\hline $\begin{array}{l}\text { 9. Estimulação } \\
\text { da autoeficácia } \\
\text { (confiança) }\end{array}$ & / & Desafios (autoestima) & Confiança & $\begin{array}{l}\text { Crenças de } \\
\text { autoeficácia }\end{array}$ \\
\hline $\begin{array}{l}\text { 10. Relevância } \\
\text { da atividade }\end{array}$ & / & / & Relevância & / \\
\hline
\end{tabular}

Fonte: os autores com base em Alves e Battaiola (2011); Csikszentmihalyi (1990); Bandura (2016); Malone e Lepper (1987); Keller (2010)

Nota-se que neste estudo o foco está nos jogos digitais educacionais, porém os componentes de motivação elencados na proposta são aplicáveis para outros artefatos educacionais como, por exemplo, animações, livros digitais, ambientes virtuais de aprendizagem, entre outros. Os componentes revisados e ampliados neste estudo estão organizados e descritos na tabela 4. 
Tabela 4 - Componentes de motivação com base na sobreposição dos estudos mapeados

\section{Componente de motivação Descrição}

Inserção de desafios

Objetivos claros

Feedback das ações

Apelo emocional
Estão associados aos objetivos da atividade e precisam ser configurados e percebidos como superáveis pelo indivíduo. Isto é, configurados em um nível intermediário (nível ótimo) em relação as habilidades e perfil cognitivo do indivíduo. Além disso, os desafios são mais efetivos para a motivação quando associados à objetivos com resultados inesperados. Nos jogos, esse balanceamento entre os desafios e as habilidades do jogador, pode ser configurado por meio de fases ou etapas compostas por níveis de dificuldade. Assim, os objetivos são intensificados progressivamente, em consonância com a evolução das habilidades do jogador.

Estão associados aos desafios e devem ser apresentados na atividade de modo claro para o indivíduo. Da mesma forma que os desafios, os objetivos possuem diferentes níveis de dificuldade, desde os mais simples, intermediários e complexos (mas superáveis). Nos jogos, os objetivos estão associados ao sistema de jogo e suas regras. Assim, em especial no contexto do jogo educacional se faz necessário informar e orientar o jogador sobre os objetivos de jogo, suas possibilidades de ação e os propósitos da tarefa.

Está associado aos desafios e objetivos da atividade, é o mecanismo responsável por informar o usuário sobre o seu desempenho. Assim, este é necessário para que tanto os objetivos como os desafios sejam motivadores. Nos jogos, o feedback orienta o jogador sobre as suas ações pelas informações da interface, o que gera a estimulação para a realização de desafios propostos pelo sistema, bem como auxilia a manter o jogador interessado pelos desafios.

Está associado à atenção, assim atua como um intensificador do interesse e engajamento do usuário para a atividade, ao buscar capturar sua atenção por meio da fantasia e da imaginação. Tal componente permite que o usuário se concentre por total na tarefa e esqueça as preocupações externas à atividade. Esse recurso, pode ser adotado com uma forma de persuadir o usuário sobre suas capacidades durante uma atividade, ao utilizar estímulos sonoros ou visuais. Nos jogos, o apelo emocional pode surgir da narrativa, dos personagens, bem como de outros estímulos lúdicos. Esses estímulos buscam chamar a atenção, instigar a curiosidade, estimular a imaginação e salientar as capacidades do jogador.

Está associado em como a informação é compreendida pelo usuário. Portanto, representa as estratégias adotadas para facilitar o processamento cognitivo do usuário em uma atividade. Por exemplo, por meio do uso de metáforas ou analogias, é possível facilitar para o usuário a integração dos novos conteúdos com os conhecimentos prévios já fixados em sua memória. Além disso, tais recursos estimulam a curiosidade do usuário para a tarefa. Assim como no item anterior (apelo emocional), este componente permite auxiliar o usuário cognitivamente ao estimular suas crenças de autoeficácia, por meio de estímulos sonoros ou visuais. Nos jogos, este componente contempla a interface virtual e a configuração dos seus elementos gráficos para facilitar a interação do jogador com as atividades de jogo. 
Curiosidade sensorial

\section{Controle sobre a atividade}

Estimulação da autoeficácia (confiança):
Está associada à percepção do usuário, ou seja, aspectos que fomentam a concentração na tarefa por meio da união pessoa e atividade (concentração). Por exemplo, o uso de uma expressão visual específica (padrão estético), ou aspectos sonoros associados à transmissão da informação podem atrair a atenção do usuário e facilitar a sua concentração. Este componente também permite estimular as crenças de autoeficácia do usuário por meio de estímulos sensoriais. Nos jogos, a linguagem gráfica recebe destaque durante a interação do jogador com o mundo ficcional de jogo, assim ela atua significativamente sobre sua motivação para o jogar;

Está associado às possibilidades de alterações na atividade pelo usuário. Assim, atua na atividade fornecendo a sensação de controle ao usuário, ao permitir a ele determinados controles e escolhas na realização das atividades. Ou seja, o usuário percebe a atividade como passível de alteração com base nas suas possibilidades de escolha. Nos jogos, possibilitar controle e poder de decisão nas atividades gera uma sensação positiva de liberdade ao jogador. Por exemplo, a escolha de personagem, qual fase será jogada primeiro, são exemplos do componente controle na esfera dos jogos;

Está associado à confiança do usuário em suas habilidades diante de uma determinada atividade. Assim, são necessárias estratégias para fomentar as crenças de autoeficácia do usuário na atividade, isto é, que ele confie em suas competências para obter êxito na atividade. Nos jogos, essa construção pode ocorrer ao ofertar experiências contínuas de sucesso para o jogador, com feedback positivo de seu desempenho principalmente no início de um conteúdo. Ou seja, busca-se evidenciar para o jogador que ele pode aprender o conteúdo e ter uma experiência de sucesso com base em suas habilidades e esforço;

Está associado à relação entre o objetivo da tarefa e os interesses internos do usuário. Ou seja, por meio desse componente se busca tornar a atividade relevante para o usuário. Nesse sentido, argumenta-se que nem sempre um aprendiz achará relevante aprender aritmética, por exemplo. Contudo, a opinião ou percepção desse aprendiz sobre o conteúdo em questão, pode mudar em razão de como a atividade é apresentada e configurada. Nos jogos educacionais, o componente relevância pode ser construído com base no mundo ficcional de jogo e associado aos aspectos lúdicos característicos dos jogos (e.g. narrativa, cenários, personagens, recompensas);

Está associada ao estado de fluxo, isto é, a concentração total na atividade, perda da consciência do mundo real, foco na situação de jogo e transformação da sensação de tempo do usuário. O estado de fluxo propicia um alto nível de engajamento na atividade. Além disso, associa-se a sensação de satisfação do usuário, o que torna as suas ações naturais, espontâneas e prazerosas. Nos jogos, o estado de fluxo e a satisfação têm maiores chances de ocorrer quando os outros componentes descritos nesta lista forem contemplados. Ademais, a sensação de satisfação gerada pelo estado de fluxo é um dos fatores centrais para manter motivação em uma atividade.

Imersão (satisfação) (1987); Keller (2010)

Fonte: os autores com base em Alves e Battaiola (2011); Csikszentmihalyi (1990); Bandura (2016); Malone e Lepper

Por fim, na tabela 5 gerou-se uma possível associação entre os componentes de motivação 
interconectados e, portanto, muitos dos elementos de jogo podem atuar em mais de um componente motivacional, bem como essa associação é variável em razão da particularidade de cada jogo. Contudo, o intuito é exemplificar e clarificar essa relação. Nota-se que no exemplo os elementos educacionais fazem parte de todos os componentes de motivação, uma vez que os aspectos educacionais são os norteadores para a configuração de todos os elementos de jogo. Além do mais, ressalta-se que a motivação está no aprendiz e não nos elementos de jogo. Porém, os elementos de jogo, com base em como são configurados, podem auxiliar a promover, bem como manter a motivação do aprendiz durante o uso do jogo educacional.

Tabela 5: Relação entre os componentes de motivação e os elementos de jogo

\begin{tabular}{|c|c|c|c|}
\hline Elementos educacionais & Componentes de motivação & Elementos formais & Elementos dramáticos \\
\hline \multirow{10}{*}{$\begin{array}{l}\text { Objetivos educacionais } \\
\text { Abordagem instrucional } \\
\text { Teoria de aprendizagem }\end{array}$} & Inserção de desafios & $\begin{array}{l}\text { Mecânicas } \\
\text { Procedimentos }\end{array}$ & $\begin{array}{l}\text { Desafio } \\
\text { Conflito }\end{array}$ \\
\hline & Objetivo claros & $\begin{array}{l}\text { Objetivos } \\
\text { Regras } \\
\text { Componentes }\end{array}$ & / \\
\hline & Feedback das ações & $\begin{array}{l}\text { Interface virtual } \\
\text { Informação }\end{array}$ & Recompensas \\
\hline & Apelo emocional & $\begin{array}{l}\text { Tema } \\
\text { Fronteiras } \\
\text { Contexto }\end{array}$ & \multirow{3}{*}{$\begin{array}{l}\text { Mundo ficcional } \\
\text { Narrativa } \\
\text { Brincar } \\
\text { Premissa } \\
\text { Arco dramático } \\
\text { Personagem }\end{array}$} \\
\hline & Processamento cognitivo & $\begin{array}{l}\text { Interface virtual } \\
\text { Tema }\end{array}$ & \\
\hline & Curiosidade sensorial & $\begin{array}{l}\text { Interface virtual } \\
\text { Tema } \\
\text { Fronteiras }\end{array}$ & \\
\hline & Controle sobre a atividade & $\begin{array}{l}\text { Procedimentos } \\
\text { Regras }\end{array}$ & / \\
\hline & Estimulação da autoeficácia & $\begin{array}{l}\text { Interface virtual } \\
\text { Informação }\end{array}$ & Recompensas \\
\hline & Relevância da atividade & $\begin{array}{l}\text { Tema } \\
\text { Informação }\end{array}$ & Recompensas \\
\hline & Imersão satisfação & $\begin{array}{l}\text { Configuração dos } \\
\text { elementos }\end{array}$ & $\begin{array}{l}\text { Configuração dos } \\
\text { elementos }\end{array}$ \\
\hline
\end{tabular}

Fonte: os autores

\section{Considerações finais}

Como resultado principal este artigo gerou uma categorização para os componentes de motivação do aprendiz-usuário do jogo digital educacional, o que atende ao objetivo previamente estipulado. Para tanto, a proposta está alicerçada em um estudo teórico, que contemplou quatro 
teorias centrais sobre motivação: teoria do fluxo (CSIKSZENTMIHALYI, 1990); Construto da Autoeficácia (BANDURA, 2016); Taxonomia proposta por Malone e Lepper (1987); Modelo ARCS (KELLER, 2010).

Além disso, a proposta aqui apresentada caracteriza-se como um desdobramento da pesquisa realizado por Alves e Battaiola (2011), a qual foi revista e ampliada ao expandir o escopo para outros subsídios teóricos.

Argumenta-se que a proposta demonstra-se ser promissora para o estudo da motivação do aprendiz com o uso de jogos digitais educacionais. Nesse sentido, como parte da tese do primeiro autor deste estudo, a proposta aqui apresentada vem sendo utilizada para verificar as informações motivacionais com crianças durante o uso de jogos digitais educacionais. Ademais, observa-se que os componentes e as informações teóricas aqui articuladas são aplicáveis também durante o processo de design e de avaliação de jogos digitais educacionais. Destaca-se ainda que apesar da proposta ter o seu foco em jogos digitais educacionais, visualiza-se a sua incorporação para outros artefatos educacionais como, por exemplo, animações, ambientes virtuais de aprendizagem, etc.

Entretanto, em razão do caráter exploratório deste artigo, estudos futuros ainda são necessários para um maior detalhamento da proposta, bem como para verificar a sua aplicabilidade com equipes de game design, de modo a realizar possíveis ajustes necessários.

Agradecimento: Ao programa de bolsas CAPES e ao CNPq pelo apoio ao projeto "Design de jogos para crianças com discalculia do desenvolvimento", processo 409770/2016-7.

\section{Referências}

ABT, C. C. Serious games. University Press of America, 1987.

ALVES, M. M.; BATTAIOLA, A. L. Recomendações para ampliar motivação em jogos e animações educacionais. In: X Simpósio Brasileiro de Games e Entretenimento Digital- SBGames. Salvador-BA, 2011.

ARNSETH, H. C. Learning to play or playing to learn: A critical account of the models of communication informing educational research on computer gameplay. Game Studies, 6(1). 2006.

BANDURA, A. Moral disengagement: How people do harm and live with themselves. Worth Publishers, 2016.

BZUNECK, J. A. As crenças de auto-eficácia e o seu papel na motivação do aluno. A motivação do aluno: contribuições da psicologia contemporânea, v. 2, p. 116-133, 2001.

CHAMBERLIN, B.; TRESPALACIOS, J.; \& GALLAGHER, R. The learning games design model: immersion, collaboration, and outcomes-driven development. International Journal of GameBased Learning (IJGBL), 2(3), p. 87-110, 2012.

CLUA, E. W. G.; BITTENCOURT, J. R. Uma nova concepção para a criação de jogos educativos. Simpósio Brasileiro de Informática na Educação, v. 36, 2004.

CSIKSZENTMIHALYI. M. Flow: the psychology of optimal experience. USA: Harper Perennial 
Modern Classics edition, 1990.

DE FREITAS, S.; LIAROKAPIS, F. Serious games: a new paradigm for education?. In: M. Ma, A. Oikonomou, and L. C. Jain, eds. Serious Games and Edutainment Applications. Springer London, p. 9-23, 2011.

FULLERTON, T.; SWAIN, C.; HOFFMAN, S. Game design workshop: Designing, prototyping, \& playtesting games. CRC Press, 2004.

GUIMARÃES, S. D. R.; BZUNECK, J. A. Propriedades psicométricas de um instrumento para avaliação da motivação de universitários. CIÊNCIAS \& COGNIÇÃO, Rio de Janeiro, v.13, n.1, p.101-113, 2008.

HABGOOD, M. J; AINSWORTH, S. E. Motivating children to learn effectively: Exploring the value of intrinsic integration in educational games. The Journal of the Learning Sciences, v. 20, n. 2, p. 169206, 2011.

JÄRVINEN, A. Games without frontiers: Theories and Methods for Game Studies and Design. 2008. 418f. Tese (Doutorado em Mídia e Cultura) - University of Tampere, Tampere. 2008.

KAPP, K. M. The gamification of learning and instruction: game-based methods and strategies for training and education. San Francisco: CA. Pfeiffer, 2012.

KELLER, J. M. Motivational design for learning and performance: The ARCS model approach. Springer Science \& Business Media, 2010.

LEMOS, A.; CUNHA, P. Olhares sobre a Cibercultura. Sulina, Porto Alegre, p. 11-23, 2003.

MALONE, T. W.; LEPPER, M. R. Making learning fun: A taxonomy of intrinsic motivations for learning. Aptitude, learning, and instruction, v. 3, n. 1987, p. 223-253, 1987.

MATTAR, J. Games em educação: como os nativos digitais aprendem. São Paulo: Person Prentice Hall. 2010.

MAYER, R. E. Computer games for learning: An evidence-based approach. London, England: MIT Press, 2014.

PRENSKY, M. Aprendizagem baseada em jogos digitais. São Paulo: Senac, 2012.

REEVE, J. Understanding motivation and emotion. John Wiley \& Sons, 2009.

SAVI, R. Avaliação de jogos voltados para a disseminação do conhecimento. 2011. 236f. Tese (Doutorando em Engenharia e Gestão do Conhecimento) - Universidade Federal de Santa Catarina, Florianópolis, 2011.

TOBIAS, S.; FLETCHER, J. D.; BEDIOU, B.; WIND, A. P.; CHEN, F. Multimedia learning from computer games. In R. E. Mayer, Ed. The Cambridge handbook of multimedia learning, 2nd ed., New York, NY: Cambridge University Press, p. 762-784, 2014.

WINN, B. The design, play, and experience framework. Handbook of research on effective electronic gaming in education, 3, p. 1010-1024, 2008. 